OPEN ACCESS

Edited by:

Ákos Pogány,

Eötvös Loránd University, Hungary

Reviewed by:

Michael Joseph Ryan,

The University of Texas at Austin,

United States

Fabio Santos Nascimento, University of São Paulo Ribeirão

Preto, Brazi

${ }^{*}$ Correspondence:

Theodora Fuss

theodora.fuss@uni-siegen.de

Specialty section:

This article was submitted to Behavioral and Evolutionary Ecology,

a section of the journal

Frontiers in Ecology and Evolution

Received: 29 July 2021

Accepted: 12 October 2021

Published: 05 November 2021

Citation:

Fuss T (2021) Mate Choice, Sex

Roles and Sexual Cognition in Vertebrates: Mate Choice Turns Cognition or Cognition Turns Mate Choice? Front. Ecol. Evol. 9:749495. doi: $10.3389 /$ fevo.2021.749495

\section{Mate Choice, Sex Roles and Sexual Cognition in Vertebrates: Mate Choice Turns Cognition or Cognition Turns Mate Choice?}

\author{
Theodora Fuss* \\ Department of Chemistry-Biology, Institute of Biology, University of Siegen, Siegen, Germany
}

The idea of "smart is sexy," meaning superior cognition provides competitive benefits in mate choice and, therefore, evolutionary advantages in terms of reproductive fitness, is both exciting and captivating. Cognitively flexible individuals perceive and adapt more dynamically to (unpredictable) environmental changes. The sex roles that females and males adopt within their populations can vary greatly in response to the prevalent mating system. Based on how cognition determines these grossly divergent sex roles, different selection pressures could possibly shape the (progressive) evolution of cognitive abilities, suggesting the potential to induce sexual dimorphisms in superior cognitive abilities. Associations between an individual's mating success, sexual traits and its cognitive abilities have been found consistently across vertebrate species and taxa, providing evidence that sexual selection may well shape the supporting cognitive prerequisites. Yet, while superior cognitive abilities provide benefits such as higher feeding success, improved antipredator behavior, or more favorable mate choice, they also claim costs such as higher energy levels and metabolic rates, which in turn may reduce fecundity, growth, or immune response. There is compelling evidence in a variety of vertebrate taxa that females appear to prefer skilled problem-solver males, i.e., they prefer those that appear to have better cognitive abilities. Consequently, cognition is also likely to have substantial effects on sexual selection processes. How the choosing sex assesses the cognitive abilities of potential mates has not been explored conclusively yet. Do cognitive skills guide an individual's mate choice and does learning change an individual's mate choice decisions? How and to which extent do individuals use their own cognitive skills to assess those of their conspecifics when choosing a mate? How does an individual's role within a mating system influence the choice of the choosing sex in this context? Drawing on several examples from the vertebrate world, this review aims to elucidate various aspects associated with cognitive sex differences, the different roles of males and females in social and sexual interactions, and the potential influence of cognition on mate choice decisions. Finally, future perspectives aim to identify ways to answer the central question of how the triad of sex, cognition, and mate choice interacts.

Keywords: fitness, behavioral flexibility, personality, sexual selection, social cognition, cognitive mate choice, cognitive flexibility, sexual dimophism 


\section{SEXUAL DIMORPHISMS IN COGNITIVE PERFORMANCE - DO SEXES DIFFER?}

'Cognition' is frequently defined as the neuronal processes principally involved in the acquisition, processing, retention, and use of information (Shettleworth, 2001; Dukas, 2004). Another important criterion for cognitive ability is the aptitude to learn and to establish associations between different stimuli (Giurfa et al., 2001). In the context of this review, I would like to describe cognition as cognitive processes that comprise thinking, reasoning, perceiving, imagining, and remembering to the extent that they involve the use of concepts (Bayne et al., 2019). Furthermore, cognition is inherent to the ability of adaptive behavioral plasticity, and is thought to shape and modulate evolutionary dynamics and, possibly, the limits of adaptation profoundly (e.g., Sznajder et al., 2012; Snell-Rood, 2013). For instance, depending on how complex a species' habitat, social environment, or life history is, the more cognitively demanding it is to survive and cope with its challenges. Cognitively flexible individuals perceive and respond more rapidly to (unpredictable) environmental changes. To give a prominent example, a welldeveloped ability to learn spatially seems to play a prominent role in mate search and mate choice in both vertebrates (e.g., Sherry et al., 1992; Geary, 1995; Kotrschal et al., 2015; CorralLópez et al., 2017) and invertebrates (e.g., Papaj and Prokopy, 1989; Dukas, 2005).

Sex roles that females and males play within their population (influenced e.g., by age or social status) can vary tremendously in response to the prevailing mating system. Depending on how cognition determines these highly distinct sex roles, different selection pressures could possibly influence the (progressive) development of cognitive abilities, thereby perhaps inducing sexual dimorphisms in superior cognitive capabilities (Galea et al., 1996; Jacobs, 1996; Johnstone et al., 1996; Lindenfors et al., 2007; Edward and Chapman, 2011). Thus, a species' mating system appears to be a major driver of cognition, with sexual selection being a key determinant of cognitive evolution. It may act directly by promoting superior cognitive abilities during mating competition, for instance, with one sex opting for the other based on a behavioral trait that is strongly influenced by cognition (e.g., solving foraging tasks). For instance, males possibly prefer females with better cognitive abilities in mutual mate choice or sex-reversed species (although this question has only been investigated with females being the choosing sex). Social and sexual interactions as well as the mating system, which attributes distinct responsibilities to each sex ranging from courtship and mate choice to nurturing the offspring, are particularly important for ample cognitive differences (Boogert et al., 2011b; Baur et al., 2019).

Interestingly, sexual dimorphisms in cognitive performance have been observed in a number of different species representing a variety of taxa. Although a number of studies examined cognitive sex differences in various different tasks and primarily independent of a mate choice or reproductive context, their findings have been attributed frequently to result from divergent sex roles. To mention a few examples, females frequently showed greater cognitive flexibility and lower persistence than males in response to new situations in a number of mammal, bird, and fish species (e.g., Ha et al., 2011; Lucon-Xiccato and Bisazza, 2014; Roelofs et al., 2017), while generally better spatial orientation skills were often attributed to males. For instance in humans, males performed better than females in spatial navigation tasks (e.g., Sherry and Hampson, 1997; Moffat et al., 1998), which appears to be the most consistent sex difference in cognition in humans and other mammals (Moffat et al., 1998; Jones et al., 2003; Jones and Healy, 2006). Male guppies (Poecilia reticulata) quickly learned to swim through a complex maze, in which guppies had to choose between alternative routes to reach the target, while their conspecific females failed to do so (Lucon-Xiccato and Bisazza, 2017a,b).

However, there are also examples to the contrary. Female guppies were observed to outperform males (a) in a spatial orientation task requiring them to learn to select the correct arm of a T-maze to rejoin a group of conspecifics and (b) in a numerical task requiring them to discriminate between 5 and 10 dots to obtain a food reward (Petrazzini et al., 2017). Although male ravens (Corvus corax) were better than females in a color discrimination test, they were inferior in a spatial discrimination task (Range et al., 2006). Female cowbirds (Molothrus ater) possess superior spatial learning abilities compared to their male counterparts (Astié et al., 1998; Guigueno et al., 2014) as they need to find and recruit host nests, in which to place their eggs. Furthermore, accumulating evidence point to selection acting on spatial memory in foodcaching bird species (Krebs et al., 1989; Roth et al., 2011; Cauchoix and Chaine, 2016; Sonnenberg et al., 2019). Female great tits clearly excelled males in an observational memory task, in which caged great tits were allowed to observe foodcaching marsh tits in an indoor aviary before they were allowed to search themselves. Female great tits were as successful at retrieving the cached food as the hoarding marsh tits themselves (Brodin and Urhan, 2015). In summary, the extent of the observed sex differences reported on many species of different taxa appears to depend tightly on the task to be solved and, hence, the cognitive competence involved. While female guppies appeared to be behaviorally more flexible (Laland and Reader, 1999; Lucon-Xiccato and Bisazza, 2014; Lucon-Xiccato and Bisazza, 2017a,b), male Atlantic mollies (Poecilia mexicana) clearly outperformed their female conspecifics both in social and asocial trial and error learning of a simple visual color discrimination task followed by a series of reversal learning (Fuss and Witte, 2019; Fuss et al., 2020). Despite the convergence of their learning performance in numerical discrimination experiments, male and female western mosquitofish (Gambusia affinis) differed in their cognitive-behavioral responses that could possibly be attributed to different sexual selection pressures (Etheredge et al., 2018).

Additional key determinants comprise cognitive style (i.e., "the way individuals acquire, process, store, or respond to information regardless of their cognitive ability", Sih and Del Giudice, 2012) and cognitive performance (i.e., accuracy of behavioral output on a learning task, Shettleworth, 2010). Sex-specific associations between the cognitive style, which is essentially determined by an individual's personality, the training 
context (i.e., using automated devices such as a Skinner box vs. ecologically more natural training procedures), and the cognitive performance have been observed frequently as well (e.g., Gatto et al., 2020; Griebling et al., 2020; Wallace et al., 2020; Wallace and Hofmann, 2021). In summary, we find strong evidence to support context-dependent differences in cognitive abilities between both sexes. In particular, contextdependency addressing different 'cognitive domains' appears to reflect the respective innate social and/or sexual role, for instance in reproduction.

\section{SOCIAL COGNITION IN A MATE CHOICE CONTEXT}

Numerous studies indicate that females select mates based on male cognitive traits. Associations between an individual's mating success and its cognitive abilities (Shohet and Watt, 2009; Keagy et al., 2009, 2011; Cauchard et al., 2013; Preiszner et al., 2017) as well as between its cognitive abilities and sexual traits (Karino et al., 2007; Boogert et al., 2008, 2011b; Mateos-Gonzalez et al., 2011; Keagy et al., 2012; Fabre et al., 2014; Minter et al., 2017) have been reported across species and taxa, suggesting that sexual selection may well shape the supporting cognitive prerequisites (Andersson and Simmons, 2006; Boogert et al., 2011b; Sewall et al., 2013; Isden et al., 2013). Yet, there is, of course, contrary evidence where cognitive ability was not the decisive criterion (e.g., Sewall et al., 2013; Templeton et al., 2014; Anderson et al., 2017). For instance, another study on spotted bowerbirds found no association between mating preference and general cognitive ability or improved performance in obstacle clearance or shape discrimination (Isden et al., 2013). Starlings reared under developmental stress showed a comparable cognitive performance to naturally reared conspecifics in a foraging task, but lower sexual signaling (song performance; Farrell et al., 2012; Peters et al., 2014).

However, superior cognitive abilities do not only provide benefits such as a higher feeding success, a better antipredator behavior, or a superior mate choice, but also demand higher energy levels and metabolic rates (due to well-developed neuronal prerequisites), which possibly decrease fecundity, growth, and immune response. Alongside possible cognitive sex differences, aspects of social cognition have been examined carefully as well. Social cognition implies both social recognition (i.e., acquisition of direct or indirect social information about others) as well as social learning (i.e., retrieving social information from others) from individuals sharing the same sex and, thus, the same social role. Using social information for mate choice to ultimately choose the best possible, maybe 'perfect' mate is particularly important when determining where to look for prospective mates, whom to avoid or pair with, how to distinguish and classify different individuals, and involves integrating and processing multimodal sensory inputs (compare Edward, 2015 for review; Cummings and Ramsey, 2015; Kavaliers and Choleris, 2017). This complex process is complemented by arousal and sexually incentive motivation, and accompanied by preference, responsiveness, and effort of a prospective choice, which includes the conversion of arousal into sexually determined behaviors (Jennions and Petrie, 1997; Kirkpatrick et al., 2006; Ågmo, 2011; Edward, 2015). Choosing females appear to base their mating decisions on multiple male traits (Andersson, 1994; Rosenthal, 2017).

The key features of cognition, i.e., learning and decisionmaking processes may dynamically change to adapt to new conditions in order to increase their prospects for a highquality partner. Social information, for instance, can be drawn upon when making decisions about potential partners, which may possibly allow performing 'learned mate choices'. In this context, mate choice may include personal experience with others (i.e., private or personal information) or the observation of conspecifics (i.e., public information) and may have an impact throughout an individual's entire life (reviewed in Hebets and Sullivan-Beckers, 2019). Thereby, social cognition provides a conceptual framework for mate choice or mate choice copying across taxa, including Arachnida, Insecta, Malacostraca, Aves, and Actinoperygii (compare Witte et al., 2015 and Jones and DuVal, 2019 for review). Hence, mate choice copying is another example of the supporting cognitive capability to observe, evaluate, and, if appropriate, imitate other individuals in the same way as individuals do whilst foraging for food or seeking novel habitats (Jones and DuVal, 2019). Interestingly, the prominently hypothesized fitness benefit of superior cognition suggests that smart individuals would be preferred as mates (hypothesis of sexual selection; Darwin, 1871; Jacobs, 1996; Miller and Todd, 1998; Miller, 2000; Boogert et al., 2011a,b; Peters et al., 2014), though it has rarely been examined in non-human individuals (Striedter and Burley, 2019). Moreover, it has not been explored conclusively yet, how the choosing sex judges the cognitive abilities of potential mates, which would be a necessary first step if smarter mates were preferred over their 'not-as-smart' counterparts. Consequently, cognition may also have considerable implications for sexual selection processes (Boogert et al., 2011b; Ryan et al., 2009).

\section{COGNITIVE MATE CHOICE}

\section{Mate Choice Based on Cognitive Traits?}

Animal courtship displays can be remarkably complex. They may comprise several contiguous steps, involve different modalities (e.g., visual, acoustic, odorous, and/or tactile stimuli), integrate morphological and behavioral aspects and may adapt to and/or depend on different contexts. The ability to perform extensive courtship displays, complex songs or acquire scarce resources through superior foraging and/or spatial orientation skills may be a major contributing factor for the success in outperforming competing conspecifics. Impressive and well-studied examples comprise peacock spiders that use synchronous motion displays (Girard et al., 2011, 2015) or bowerbirds and sage grouse, who adapt their courtship display intentionally in response to female signals (Patricelli et al., 2002, 2006, 2011; Patricelli and Krakauer, 2010). Similarly, in carotenoid-dependent signaling systems such as siskins, brown boobies, house finches, or sticklebacks and guppies, superior foragers produce exaggerated 
sexual signals to impress courted females (e.g., Endler, 1980, 1984; Kodric-Brown, 1985; Milinski and Bakker, 1990; Senar and Escobar, 2002; Karino et al., 2007; Mateos-Gonzalez et al., 2011; Michael et al., 2018). Therefore, in numerous taxa, males indicate their suitability as potential mates by various elaborate traits. The courted females respond with individual preferences for one or another trait. However, the complexity of the performed courtship behavior seems not to be the only determinant for choosing a suitable mate. Recent findings point to cognitive abilities underlying both 'adaptive' production and evaluation of complex courtship displays (Boogert et al., 2008, 2011a,b; Ryan et al., 2009; Keagy et al., 2012). In this context, cognitive style, i.e., the way an individual processes whatever information about its same-sex or opposite-sex conspecifics, is likely to have a substantial impact on its perception of any sexual signals. Moreover, its cognitive style determines its capability to evaluate these signals in a mate choice situation. For instance, comparisons of individual problem solving capacities within a species, especially while foraging, have shown positive correlations with fecundity (Cole et al., 2012; Wetzel, 2017). There is compelling evidence in a wide variety of taxa that females appear to prefer males who are adroit problem solvers, i.e., they prefer those who presumably have better cognitive abilities (mammals: Spritzer et al., 2005; Prokosch et al., 2009; Kavaliers and Choleris, 2017; Silk and Kappeler, 2017; birds: Keagy et al., 2009, 2011; Boogert et al., 2011b; Peters et al., 2014; MateosGonzalez et al., 2011; fish: Shohet and Watt, 2009; Minter et al., 2017; Keagy et al., 2019). Hence, I anticipate that the females' preference for males demonstrating superior cognitive abilities will increase if females experience either direct and/or indirect benefits through mating with them (Keagy et al., 2009; Boogert et al., 2011b). If an individual shift in preference does indeed yield the expected benefits and confers a reproductive advantage over non-preferring females, this may hypothetically translate into an evolutionary preference change across generations.

\section{Mammals}

In humans, superior cognitive abilities and innovativeness are generally associated with affirmative (social, sexual) life outcomes (e.g., Plomin and Deary, 2015). However, the association between innovative problem-solving capabilities and their effects on mate choice, reproduction and fitness in non-human mammals is frequently neglected. Innovativeness facilitates survival in complex or changing environments, and allows individuals to explore and colonize novel habitats (Sol et al., 2005). Despite the obvious ecological and evolutionary benefits of being innovative (Laland and Reader, 1999; Nicolakakis et al., 2003; Reader and Laland, 2003), variation within a species, between the sexes, and across different species is only starting to be studied in more detail. For instance, behavioral studies revealed that primates and hyenas share similar socio-cognitive abilities. Elevated levels of innovativeness compared to other carnivores (Benson-Amram and Holekamp, 2012; Benson-Amram et al., 2016) have been observed in wild vervet monkeys (Cercopithecus aethiops) as well as in spotted hyenas (Crocuta crocuta). Aiming to determine whether innovativeness might be an adaptive trait in (female) spotted hyenas, Johnson-Ulrich et al. (2019) analyzed innovativeness in problem-solving tests in 29 female individuals and set these alongside long-term data on their fitness, reproduction and survival. They found innovative females to reproduce more cubs; however, their cubs showed a lower probability of survival compared to the fewer cubs of noninnovators. Hence, choosing a mate with superior cognitive abilities seems to pay off initially, but does not translate into an increased likelihood of passing on one's genes to the next generation in the long run. Huebner et al. (2018) examined possible associations between body condition, survival rates, individual cognitive performance on repetitive attempts to solve a food extraction task (removing a sliding cover placed on small boxes to access a food reward), and spatial learning in a four-arm maze in wild gray mouse lemurs (Microcebus murinus). The cognitive ability to adopt a newly discovered technique to exploit novel food sources in times of scarcity quickly could provide them with significant fitness advantages. This pronounced ability should impress a female when observing and, finally, choosing a mate, as she could derive better nurturing of her offspring. However, neither the individuals' cognitive performance in both tasks correlated with each other, nor did the performance correlate with the gray mouse lemurs' survival rates (Huebner et al., 2018).

Sociality within a cohabitant community or population is also a relevant dimension in the context of cognition and mate choice. Williams et al. (2020) examined the direct and indirect effects of social position and individual behavioral traits on solving a novel puzzle box in social yellow-bellied marmots (Marmota flaviventer). Social relationships, the type of interaction and the individual role (i.e., recipient or initiator) significantly determined the way an individual interacted in cognitive tests. Interestingly, living a very social lifestyle resulted in lower reproductive success, increased hibernation mortality and, consequently, lower survival rates in female but not in male yellow-bellied marmots. Especially young females and their offspring greatly benefited from larger social groups. Again, this effect was not observed in males regardless of age (Montero et al., 2020). Conversely, the strength of affiliation was negatively associated with female annual reproductive success (Wey and Blumstein, 2012). These findings clearly indicate that social behavior, social and/or sex roles, and cognitive abilities not only play an important role during mate choice and reproduction, but also seem to translate in the probability of the own and/or the offspring's survival in a positive or negative way. Male meadow voles defend large home territories against conspecific rivals and their reproductive success is closely linked to finding females to mate with. Indeed, the courting males' spatial learning ability is considerably more pronounced compared to their conspecific females (Gaulin and FitzGerald, 1986, 1989; Galea et al., 1996). As is the case with many rodents, they typically leave their scent on prominent landmarks or along trails to ensure that they are perceived by conspecifics of both sexes. The scent marks provide various social information, such as sex, reproductive state, health condition, or social rank. The odor information targets different recipients (e.g., receptive females, competitors or heterospecifics), who in turn classify its relevance and value according to its phenotype, genotype, and intentions. 
Hence, depending on which animal encounters the scent mark, it has to compare the social odor information with memorized details and make various decisions relating to, for instance, mate choice, same-sex competition, social olfactory communication, or sperm distribution/competition. In addition to the availability of mates and resources, the own fitness, age, sex, and social position play a key role to ensure survival and to improve the own fitness. As a result, a complex, associative social memory develops to identify scent marks as being, e.g., from males or females, as known or unknown, as sexually immature or receptive. However, as scent marks of different animals may overlap, complex supporting cognitive capabilities are required to form appropriate associations and adapt behavior accordingly (Ferkin, 2011, 2018).

\section{Birds}

Many studies on mate choice in birds focus on physical traits, but aspects of individual personality and social alliances are also receiving increasing attention. In particular, in long-lived avian species, social alliances that form at pre-mature life stages (i.e., prosocial behavior) apparently lead to long-term social bonds (parenthood, long-term cooperative pair and/or group behavior) at a sexually mature age (Kaplan, 2020). Examples of prosocial bird species, who are known for their exceptional cognitive abilities, include jackdaws (Corvus monedula) (De Kort et al., 2006; von Bayern et al., 2007; Schwab et al., 2012), Eurasian jays (Garrulus glandarius) (Ostojić et al., 2013, 2014), rooks (Corvus frugilegus) (Scheid et al., 2008), common ravens (C. corax) (Di Lascio et al., 2013; Massen et al., 2015), or even African gray parrots (Psittacus erithacus) (Péron et al., 2013). In this context, sociality including its cognitive and affective dimensions, and mate choice might play a key role in birds in terms of a "pre-sexual attachment to a potential mating partner" (Kaplan, 2020).

In a wide range of avian species, strong relationships were discovered between the length of parental brood care and brain size, raising suggestions of related enhanced cognitive capabilities. These suggestions were supported by observations, for instance, in several corvids, bowerbirds, albatrosses, and cockatoos, which revealed prolonged parental guidance just until the first own brood to be an essential component in the acquisition of social and cognitive skills (Kaplan, 2020). To give an example, the sexual display of male song is generally considered a sex-specific social behavior that is learned prior to sexual maturity and presumably requires elevated cognitive skills in both sexes (Boogert et al., 2011b; Peters et al., 2014; Anderson et al., 2017). Most bird song research has been performed assuming that songbirds have evolved complex song repertoires due to the pressure of sexual selection on males that arises from both competition between males and female choice (Beecher and Brenowitz, 2005; Byers and Kroodsma, 2009). Interestingly, learned aspects of song have been found to alter female mating preferences in various songbird species (DuBois et al., 2018), although females usually do not sing themselves. It is important to note, however, that females of more than two-thirds of all songbird families also sing in contexts such as tropical dispersal, territoriality, convergent sex roles, and sexual dichromatism.
In many species, however, females have lost song secondarily (compare Odom et al., 2014 for review).

Several studies on the relationship between a male's vocal repertoire and various cognitive processes try to determine whether the male's song may provide conspecific females with information on his cognitive abilities (Boogert et al., 2011b; Sewall et al., 2013; Anderson et al., 2017). So, sex roles appear to be clearly assigned in many songbird species: while males sing as part of their courtship display, females listen to and evaluate the quality of the males' song. Although the neuronal prerequisites that guide the complex process of singing and song composition in male and female songbirds are well understood (Nowicki et al., 2002; Gobes and Bolhuis, 2007; Mooney, 2009; Jin, 2013; Sewall et al., 2013; Geberzahn and Aubin, 2014; Odom et al., 2014), there is still a lack of understanding of the relationship between song learning and other cognitive processes (Anderson et al., 2017) in the context of mate choice. Female songbirds prefer males presenting a larger vocal repertoire (Searcy, 1984; Lampe and Saetre, 1995) and song is deemed an honest signal of male quality and fitness measures. In male song sparrows (Melospiza melodia), song repertoire size correlates positively with an array of fitness traits comprising territory ownership, heterozygosity, immune system quality, longevity, and lifetime reproductive success (Reid et al., 2005; Boogert et al., 2011a). In a 20year-long-term study, Reid et al. (2005) analyzed data from free-living male song sparrows (M. melodia) in terms of song repertoire size and the number of independent and recruited offspring and grandoffspring. The larger the song repertoire was, the longer-lived the males were and the greater was their reproductive success extending into the next and even the succeeding generation. Wild female song sparrows ( $M$. melodia) prefer males with a rich vocal repertoire, which also correlates with various fitness measures (e.g., song repertoire size and different motor, color association, reversal learning or detourreaching tasks tested in captivity, Boogert et al., 2011a,b; DuBois et al., 2018). Moreover, song complexity as a sexual signal has been linked to male zebra finch performance in a novel foraging task (Taeniopygia guttata castanotis, Boogert et al., 2008). Conversely, Sewall et al. (2013) challenged song sparrow males (M. melodia) in a spatial memory task and discovered an inverse relationship between spatial memory performance and male vocal repertoire.

Associations between song repertoire size and cognitive performance were examined in wild song sparrows (M. melodia). Initially, males' song repertoires were recorded in the field. Subsequently, these males were tested in motor, color association and reversal learning, and detour-reaching tasks (Boogert et al., 2011a,b). The individuals' color association performance was positively correlated with their performance in the subsequent reversal task. Interestingly, their performance did not correlate with the other learning tasks they were challenged with. Nevertheless, males having a wider song repertoire were able to solve difficult tasks in a shorter period of time, but performed poorly in the reversal task compared to males having a more limited song repertoire (Boogert et al., 2011a,b). Yet, results remain inconclusive as no correlations were observed in 
laboratory-raised song sparrows following the same experimental agenda (Anderson et al., 2017). In a recent study, a group of 49 swamp sparrows (Melospiza giorgiana) was examined for their song quality (i.e., repertoire size, vocal performance, song learning; DuBois et al., 2018). Subsequently, song quality was compared to the performance in five different cognitive tests, comprising a novel foraging task, a color association and a reversal task, a spatial learning task, and a detour-reaching task. Unexpectedly in the context of the previous study by Boogert et al. (2011b), none of the song parameters were considered indicative of any cognitive performance level. Hence, these findings contradict the hypothesis on song properties indicating overall cognitive abilities in swamp sparrows (DuBois et al., 2018). Likewise, no associations between song repertoire and cognitive performance (detour reaching, spatial memory) were obtained when testing wild North Island robins (Petroica longipes), which are a foraging species, admittedly with a quite different ecology than sparrows (MacKinlay and Shaw, 2019). In summary, there remains controversy about the phenomenon of bird song and its implications for cognitive mate choice (compare Searcy and Nowicki, 2019 for review).

However, several studies on different bird species attempted to investigate associations between cognition and mate choice from different perspectives. In food caching New Zealand robins (P. longipes), males' memory performance in a spatial task during winter severely influenced their subsequent breeding success. Individuals with higher performance levels produced more fledglings and, subsequently, more independent offspring per nesting attempt. Males with superior memory performance spent more time in flight while foraging and provisioning, and, additionally, provided their chicks with an increased share of large prey items. These effects were absent in female robins (Shaw et al., 2019). Male bowerbirds spend a considerable amount of time building their bowers to attract females and convince them to mate. Several studies revealed that the male satin bowerbirds' mating success was positively associated with their problem-solving performance and aggregate measures of their cognitive ability (Keagy et al., 2009, 2011). The males were challenged with six different cognitively challenging tasks, including two problemsolving tasks, one mimetic repertoire task and three bowerrebuilding tasks. Although no correlations between the males' performances in different tasks were observed, females chose the overall well-performing males, thereby apparently considering information about several behavioral display traits (Keagy et al., 2012). However, Isden et al. (2013) reported conflicting observations by finding no relationship between performance on cognitive and problem-solving tasks and mating success in male spotted bowerbirds.

Two studies, one using zebra finches (T. guttata castanotis; Chantal et al., 2016) and the other using budgerigars (Melopsittacus undulatus; Chen et al., 2019) explored whether females would modify their mating preference after having observed the cognitive performance of males in a problem-solving task:

Initially, zebra finch females were challenged with a set of two males to assess their spontaneous preference for one or another
(Chantal et al., 2016). Then, both zebra finch males (i.e., the preferred and the unpreferred one) were trained to open a tube by removing the lid to access a food reward (Chantal et al., 2016). In order to manipulate their success, one male (the previously unpreferred male, now assigned to be the 'solver') was challenged with a tube the lid of which was pressed only halfway and which could be easily opened. The other male (the previously preferred male, now assigned to be the 'non-solver') was challenged with a tube the lid of which was fully pressed and, thus, was impossible to open. Subsequently, females were allowed to observe both males being challenged with the tube-opening task. In contrast to the first preference test, females preferred the solvers, i.e., the previously unpreferred males in the final second preference test. To determine (a) whether females were able to discriminate between both males and (b) whether the males' problem-solving abilities had in fact triggered the shift in female preference, all birds took part in a color association task. Females were well able to discriminate visually between the presented males, and their preference was found to be independent of the males' learning rate in this task. Considering the results of both tasks in a shared context, zebra finch females were found to significantly prefer the most skillful (i.e., the initially unpreferred) male in both tasks. As males differed in their feeding rates in both treatments, females appeared to use the males' foraging efficiency as an important criterion when choosing a mate (Chantal et al., 2016).

The other study (Chen et al., 2019) followed a similar experimental design, in which budgerigar females were challenged initially with a set of two males to assess their spontaneous preference for one or another as well. Then, nonpreferred male budgerigars were trained to open transparent boxes containing seeds. Meanwhile, the preferred males and females were exposed to already-opened containers, so they could not attempt to solve the following foraging task. Subsequently, each female was allowed to observe the trained (but initially unpreferred) males repetitively opening the boxes, while the untrained (but initially preferred) males failed. In consecutive second preference test trials, females changed their social preferences in favor of the successful, formerly unpreferred males. Control tests suggested that the females' preference shift did not only reflect the observation of trained males feeding on seeds, i.e., the males' ability to provide food. Furthermore, females showed no preference for other females trained to open the seed boxes, indicating that the main finding related to an intersexual context (Chen et al., 2019).

However, even with these two carefully designed studies, which have yielded impressive results, we cannot be entirely convinced that cognition was the main factor in the females' choice. First, neither zebra finch nor budgerigar females were allowed to attempt the problem-solving tasks (i.e., zebra finches opening tube lids or budgerigars opening boxes) themselves. Yet, in order to be able to evaluate and, subsequently, rank the males' individual abilities in solving a particular task, the judge herself needs to be aware of the complexity of the task she is now meant to assess. It is therefore difficult to predict the extent to which the zebra finch or budgerigar females were able to assess the cognitive aptitudes of the males performing the test. Second, neither zebra finch nor budgerigar females were 
allowed to observe the males while learning and, thus, examine differences in the males' learning processes. Hence, females exclusively witnessed the output of the preceding training, which was attended only by a selection of the males. Third, the zebra finch and the budgerigar males' success in problem solving was manipulated in both studies, either by closing the tubes at varying degrees of tightness (Chantal et al., 2016) or by training only the unpreferred males (Chen et al., 2019). Instead of assessing cognitive problem-solving abilities, the observing females may have interpreted the differences in males' ability to access the containers as differences in the males' physical strength (Striedter and Burley, 2019). Indeed, the training itself could have had an impact on the males' behavior. Different degrees of training might have also been a reflection of different levels of male selfconfidence or audacity in approaching the task in the female's presence, which, potentially, could have influenced her choice. For instance, the trained (initially unpreferred) males may have acted more keenly when handling the tubes or containers since they were already acquainted with the experimental setting, while the inexperienced (but initially preferred) males were not. Hence, this raises the question of the extent to which personality traits such as boldness, shyness, retentiveness, or self-confidence, i.e., an individual's cognitive style play an important role in (a) approaching cognitive tasks, and in (b) assessing cognitive abilities by potential mates. Camacho-Alpízar et al. (2020) added another perspective by questioning whether successful problemsolving can be linked to cognitive abilities at all, as "non-cognitive factors (e.g., persistence) are often correlated with problem-solving success".

\section{Fish}

Beyond mammals and birds, an increasing number of studies addresses the role of cognition in mate choice of various fish species. Relative to all vertebrate taxa, fish do not only represent the greatest species diversity, but also inhabit the most diverse physical and social environments. They are characterized by the greatest variation in brain anatomy of all vertebrates. This gives them the neuronal basis for different levels of behavioral plasticity in response to their environment. In turn, this suggests, hypothetically, an equivalently wide variety of cognitive traits relating to social interactivity and mate choice. Many fish species can flexibly adapt their physiology and behavior to cope better with challenging environmental conditions. In fact, a major component of this flexibility is supported and influenced by both cognition and neuronal plasticity (Ebbesson and Braithwaite, 2012; Herczeg et al., 2019). Novel foraging information propagates considerably faster between female guppies than between males, possibly because the reproductive success of female guppies is inherently more strongly linked to resource availability than it is the case for male guppies (Reader and Laland, 2000). Male guppies (P. reticulata) were trained to solve two different mazes to obtain a food reward (Shohet and Watt, 2009). Subsequently, female guppies were allowed to repeatedly observe several different trained males orienting within the maze. Consecutive mating preference tests as well as the time it took a male to learn both mazes were used to determine a possible association between the females' preferences and the males' learning ability. Indeed, the observing females preferred the faster-learning males, who they judged to be more attractive than the slow learners in subsequent mating preference tests. Furthermore, the females' preference was not related to the males' body size or coloring, although males of a stronger orange color solved the tasks faster than their less colorful peers. Similar to the bird studies (Chantal et al., 2016; Chen et al., 2019), guppy females were unfortunately not allowed to observe the males while learning to pass through the mazes, nor were the females themselves challenged with any maze in order to be able to judge the level of difficulty and/or the males' performance. Consequently, we cannot fully reject the objection that females may have taken into account any other, unmeasured traits such as the males' display rates (Matthews et al., 1997; Kodric-Brown and Nicoletto, 2001) or the males' general mobility (Van Oosterhout et al., 2003) to base their preference on. Results were supported by findings in sailfin tetras (Crenuchus spilurus) using a comparable test paradigm. At the same time, the highly ornamented males were considerably more neophobic than their less ornamented rivals, presumably because they experience greater predation pressure while also having a higher predicted fitness payoff (da Silva Pinto et al., 2021). Accordingly, sexual selection by means of female preference seems to result in greater cognitive abilities of smart, beautiful males, whereby cognition is becoming a vital part of their attractiveness to females.

A study on male threespine sticklebacks (Gasterosteus aculeatus) examined a very different aspect of cognition, namely inhibitory control, which may possibly be related to male sexual signals (Minter et al., 2017). Inhibitory control describes a cognitive process, which enables an individual to inhibit its natural, habitual, or dominant behavioral response to certain stimuli for adopting a more appropriate behavior to meet its intended goals (Hauser, 1999; Boogert et al., 2011b; Bray et al., 2014; Rystrom et al., 2019). In threespine sticklebacks, males provide all parental brood care, but at the same time, they need to avoid eating their own fry that closely resemble their prey. Hence, males with better inhibitory control would be more successful in rearing their offspring, resulting in higher fitness levels. Initially, male sticklebacks were challenged with a detour-reaching task. Subsequently, the males were assessed for their sexual signals (coloration, nest area and courtship vigor) to determine whether this visual information would reveal the males' cognitive abilities, which proved not to be the case. Females preferred to mate with males that showed better initial inhibitory control, suggesting that females possibly consider this male trait as a crucial trait for mate choice (Minter et al., 2017). Keagy et al. (2019) reported similar results, revealing that neophobia differences between both sexes allowed male threespine sticklebacks to consistently outperform females in a detour task. However, unlike female sticklebacks, who preferred cognitively superior males (Minter et al., 2017), male sticklebacks did not express this preference when choosing females (Keagy et al., 2019). Hence, we may derive two possible lessons: either males merely disregarded the females' cognitive performance in the present task when courting a female to mate with or the chosen detour task did not adequately reflect their preference for aspirational female cognitive skills. 
In answering the first key question 'Do cognitive skills guide an individual's mate choice and, ultimately, does learning change an individual's decisions?', we can conclude that (a) sexes differ in their cognitive abilities depending on the given challenge, presumably because of the different roles they play within their social community. This suggests that the cognitive processes governing their mate choice decisions will also differ. Moreover, we can deduce that (b) cognitive abilities indeed have a considerable influence on individual mate choice decisions in species across different taxa, and (c) the males' displays of learned behavioral patterns alter the females' mate choice decisions. We can draw these conclusions for three large vertebrate taxa - i.e., mammals, birds and fish. Further research should aim to expand our knowledge to amphibians and reptiles, which have been less extensively examined in this field so far.

\section{Preference for Mates Demonstrating Superior Cognitive Skills}

Given the current state of research as discussed above using numerous mammal, bird and fish examples, we still struggle to answer the second key question: 'How and to which extent do individuals use their own cognitive skills to assess those of their conspecifics when choosing a partner?'. Compared to their inferior conspecifics, cognitively superior individuals are frequently preferred as mates in various species across different taxa (e.g., crossbills, guppies, or humans; Keagy et al., 2009; Shohet and Watt, 2009; Snowberg and Benkman, 2009; Miller, 2011). Yet, it has rarely been investigated whether the cognitive ability per se increases the potential mate's attractiveness or whether the candidate appears to be in a better (physical) condition on account of his or her cognitive abilities, e.g., to be able to access better food sources (Riebel, 2011; Boogert et al., 2011b). Moreover, we cannot safely predict whether cognitive abilities are reflected in observable (e.g., visible) physical attributes, as seems to be the case, for instance, with nutritional status, parasite prevalence, immune competence, or social rank. Mate choice plays a key role in sexual selection, with significant fitness consequences and, presumably, profound cognitive challenges. Remarkably, however, only a limited number of studies has determined the importance of the cognitive abilities of the choosing individual to date. For instance, in food-caching wild mountain chickadees, males with superior spatial learning and memory abilities had larger clutches and greater numbers of fledged young. At the same time, superior female spatial learning and memory capabilities resulted in fledglings with greater body mass. These effects were not observed reciprocally. The disparity in reproductive investment among females appeared to reflect individual variation in spatial memory abilities on the one hand, and to integrate both their own and their mate's superior cognitive abilities on the other (Branch et al., 2019). When challenging female threespine sticklebacks with a spatial learning task and its reversal, cognitively more flexible females were observed to devote more time to assess prospective male partners in a dichotomous mate choice task. However, it were these highly motivated females, who made more mistakes at the beginning of a reversal phase, which may be due to them developing faster or more robust problem-solving routines and, subsequently, adapting more slowly to new conditions. Nevertheless, they were ultimately faster in relearning the task (Rystrom et al., 2019). Another study examined the learning accuracy of male and female rose bitterlings (Rhodeus ocellatus) in a spatial learning task in terms of the males' reproductive success (Smith et al., 2015). Following the spatial orientation task, males participated in competitive mating trials, in which they either played the role of a guardian or of a sneaker male. When evaluating the males' reproductive success via paternity analysis in association with their learning rates, high-performing sneaker males produced the most offspring. Subsequently, this learning ability was revealed hereditary to the offspring, which suggests that cognitive acuity may be subject to intra-sexual selection (Smith et al., 2015). Interestingly, superior cognitive abilities in spatial memory of male lekking long-billed hermits (Phaethornis longirostris) were favored by female choice and, consequently, played a crucial role in male mating success. Superior males were more likely territorial and the structure of their mating vocal signals was more consistent compared to their inferior male conspecifics. In summary, enhanced spatial memory as a measure of male superior cognitive ability is as important to female lekking hummingbirds as weapon (i.e., beak tip length) and body size and strength (i.e., weight lifting during vertical flight) are to territory ownership when choosing a mate to pair with (Araya-Salas et al., 2018).

The level of an individual's cognitive ability is frequently associated with its brain size (e.g., larger brains provide enhanced cognitive abilities). Aiming to examine the cognitive capabilities of guppies ( $P$. reticulata) involved in mate assessment, CorralLópez et al. (2017) hypothesized that guppy females with smaller brains would have lower cognitive capabilities than their larger-brained conspecifics, causing their mate choice to differ. Therefore, both small- and large-brained females were subjected to cognitive tests for color discrimination, condition, swimming ability and optomotor response, in which no differences were observed. However, the two groups differed significantly in their mate choice decisions regarding mate quality assessment. The authors concluded that limited cognitive abilities could be among the reasons why an individual may be either able or limited in its ability to assess the quality of a prospective mate. Although no direct association between male brain size and their overall sexual behavior was observed (Corral-López et al., 2015), males with comparatively larger brains were considerably better at discriminating differently sized females in the context of mate choice (Corral-López et al., 2018).

\section{MATE CHOICE, COGNITION AND PERSONALITY}

Adding to the complexity of the picture, an individual's cognitive abilities and mate choice decisions decisively determine its personality and vice versa. However, this review does not aim to recount studies and arguments on this broad topic in detail. Therefore, I will address this exciting topic only briefly by describing a few fish examples. Shortly, the concept 
of 'personality' covers at least three domains, comprising (1) "contextual generality" at a particular age or moment of time, (2) "temporal consistency" in and between the assessed personality traits, and (3) the impact of "genes and experience" on personality development throughout an individual's lifehistory (Stamps and Groothuis, 2010; Kaiser and Müller, 2021). Concisely, 'personality' is generally considered a "consistent between-individual variation in clusters of behavioral traits independent of factors such as age or sex" (Mather and Carere, 2019). The growing body of evidence suggests that an animal's personality contours both its cognitive style and performance as a function of the relevant 'cognitive domain'. For instance, an animal can approach a given task quickly and boldly, or, alternatively, slowly and cautiously, while possibly acting more precisely. These behavioral patterns have been and are still used to anticipate an individual's performance. The nature of the task, i.e., which cognitive domain should be addressed (e.g., spatial learning or memory, color discrimination, counting) also plays a pivotal role. An increasing number of studies attempted to establish a link between these facets (e.g., Carere and Locurto, 2011; Sih and Del Giudice, 2012; Guillette et al., 2017; Dougherty and Guillette, 2018; Wallace et al., 2020). Yet, animal personality traits have been reported in a variety of both vertebrates (mammals: Malmkvist and Hansen, 2002; Sih and Bell, 2008; Réale et al., 2009; birds: Groothuis and Carere, 2005; Portugal et al., 2017; reptiles and amphibians: Cote et al., 2008; Kelleher et al., 2018; Sih et al., 2018; fish: Toms et al., 2010 for review; Kareklas et al., 2016; Jolles et al.,
2019) and invertebrates (ground beetles: Labaude et al., 2018; cuttlefish: Zoratto et al., 2018, bees: Walton and Toth, 2016; cockroaches: Stanley et al., 2017; compare also Mather and Logue, 2013 for review). In addition to influencing an individual's cognitive style and performance, the courting and the choosing individuals' personalities frequently affect mate choice decisions. Thereby, different personality types and, possibly, different social and/or sex roles may persist within populations (e.g., paternal, maternal or joint brood care and feeding of the young, paternal defense of the nest and/or the caring partner, territory marking, averting of predators). Darwin (1871) already noted that "when we behold two males fighting for the possession of the female, or several male birds displaying their gorgeous plumage, and performing strange antics before an assembled body of females, we cannot doubt that, though led by instinct, they know what they are about, and consciously exert their mental and bodily powers. [...] Our difficulty in regard to sexual selection lies in understanding how it is that the males which conquer other males, or those which prove the most attractive to the females, leave a greater number of offspring to inherit their superiority than their beaten and less attractive rivals".

There is still very little information on how the triad of mate choice, cognition and personality interacts in the light of the sexes' roles yet. Considering the key questions of this review, suffice it to say that the personality phenotypes of the interacting individuals and, by implication, assortative or disassortative mate choice strategies appear to play an

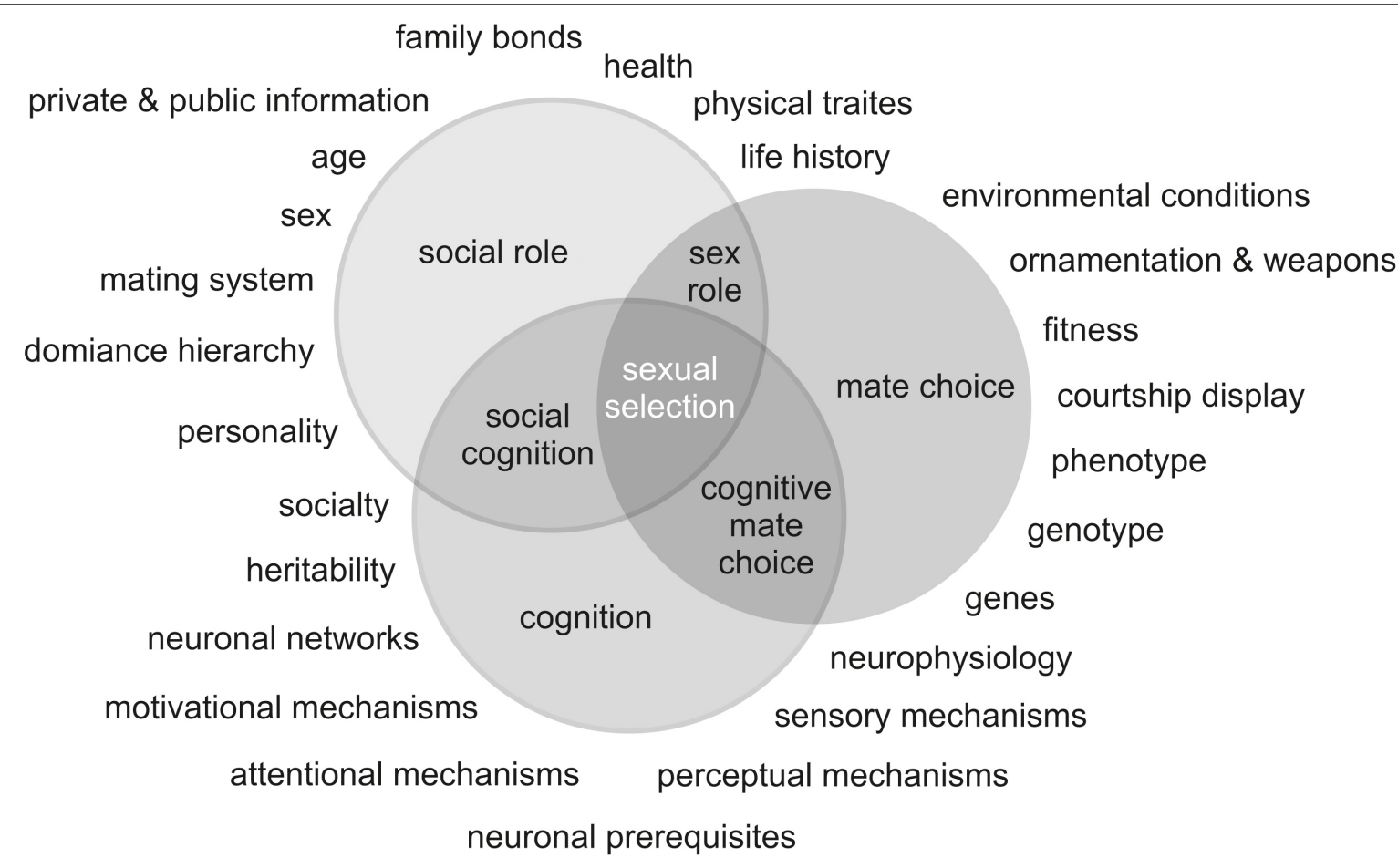

FIGURE 1 | Mate choice, cognition, and social roles converge on social cognition, cognitive mate choice, and sex roles, which are mutually dependent on one another as well as on various powerful determinants, and represent important determinants of sexual selection. 
intriguing role in many taxa. Depending on a species' respective environmental conditions, assortative mate choice of similarly behaving individuals or disassortative mate choice of apparently antagonistic, but complementary behaving individuals may be favored (mammals: e.g., Ihara and Feldman, 2003; Massen and Koski, 2014; Rangassamy et al., 2015; Martin-Wintle et al., 2017; birds: e.g., Both et al., 2005; van Oers et al., 2008; Schuett et al., 2011; Gabriel and Black, 2012; Horton et al., 2012; Fox and Millam, 2014; Pogány et al., 2018; Clermont et al., 2019; Collins et al., 2019; fish: e.g., Ariyomo and Watt, 2013; Laubu et al., 2017; Scherer et al., 2017; Schweitzer et al., 2017; Chen et al., 2018; invertebrates: e.g., Kralj-Fišer et al., 2013; Montiglio et al., 2016; Baur et al., 2019). This could be a decisive competitive advantage both genotypically and phenotypically in the context of bi-parental brood care. From this brief glimpse into the complex world of cognition, personality and mate choice, we can imagine the extent to which these three dimensions (a) influence each other, (b) influence sex roles within a mating system and, in turn, (c) are influenced by sex roles depending on the (social/sexual) context (but compare Munson et al., 2020 for an comprehensive review on mate choice and behavioral types).

\section{CONCLUSION AND FUTURE PERSPECTIVES}

This review sought to answer a number of key questions. Aiming to answer the first question, 'Do cognitive abilities guide an individual's mate choice and, ultimately, does learning alter an individual's mate choice decisions?', evidence was provided to support the strong influence of an individual's role, determined by its sex, social status, mating system, and cognitive performance on mate choice decisions. Additionally, the males' displays of learned courtship seem to alter the females' mate choice decisions. Subsequently, findings gave rise to further questions: 'How and to which extent do individuals use their own cognitive skills to assess those of their conspecifics when choosing a partner?', and 'How does an individual's role within the mating system influence the choice of the choosing sex in this context?'. Sexual selection and mate choice take place within a complex framework of an animal's social interactions. Several determinants such as environmental conditions, cognitive abilities, dominance hierarchies, family bonds, age, or sex of the individuals involved markedly affect these interactions. The determinants, in turn, depend on an individual's social role and, more precisely, the distinct role of its sex in its social surroundings. Additionally, attentional, motivational, sensory and perceptual mechanisms depend on the corresponding neuronal prerequisites inherent to every individual. These mechanisms are known to exhibit substantial differences between sex and species, but are vital (a) to survival, cooperation and reproduction, and (b) to social interaction (Figure 1). The role of learning in the acquisition of traits that are targets of mate choice and the consequences of superior cognitive capabilities on this central evolutionary process were carefully elucidated. In this context, males and females may possibly resort to divergent optima in their (domain-specific) cognitive traits, which are shaped by different life history strategies and different experiences at different life stages. However, any individual regardless of sex and social role could potentially be limited in achieving its best cognitive performance due to social constraints and/or sexual conflicts within its mating system.

Sex-role inversed species constitute another yet understudied dimension to this review's topic. In role-inversed species such as pipefish or seahorses, males provide the higher investment in the offspring by carrying eggs internally. Similar to the conventional mating systems that have been discussed so far, males choose depending on the female's body size and the intensity of her courtship display (Berglund et al., 1986a,b; Vincent et al., 1992; Berglund and Rosenqvist, 2003; Barlow, 2005; Berglund et al., 2005). In these species, females are likely to be the brighter, more colorful sex. However, the social framework and the physiological prerequisites underlying the development of these role reversals have been and remain widely discussed (e.g., Beal et al., 2018; Mobley et al., 2018; Anderson et al., 2020; Lipshutz and Rosvall, 2020). Possible interactions between their mate choice and the impact of superior or inferior cognitive abilities of the choosing or the chosen sex constitute fascinating future research topics.

Benefiting from many examples mostly from three major vertebrate groups, this review summarizes a large number of studies that attempt to elucidate many different aspects relating to cognitive sex differences, the different roles of males and females in social and sexual interactions, and the potential influence of cognition on mate choice decisions. Nevertheless, the central question of how this triad interacts remains partially unanswered. Most studies commence with a first mate choice test to discriminate preferred and unpreferred potential mates. Subsequently, the unpreferred individuals of the sex to be chosen are trained in any type of problem-solving task. Following the presentation of their acquired skills, a second mate choice test is performed to reveal a potential preference shift in the choosing sex. There is virtually never an equal training of both potential mates (i.e., preferred and non-preferred individuals) or of the individuals of the choosing sex in the assigned task. However, this approach does not take into account any possible reflection of cognitive abilities in distinct physical, physiological, or morphological characteristics or in specific behavioral patterns that are not known to us yet but may well be perceived by the selecting sex of the observed test species. Thus, if only a subset of individuals performing a particular role receive training, this may inadvertently but disturbingly bias test results caused by an inadequate testing paradigm. Having said that, are animals even capable of accurately judging the cognitive abilities of potential mates in solving a particular task if they themselves have never learned the task they now assess? How should they judge the degree of difficulty and assess the problem-solving skills of a potential mate they do not even know themselves? Therefore, prior to the second mate choice test, all participants, regardless of the role assigned to their sex (i.e., choosing or courting sex in their respective mating system), should be trained to test their performance and assess their cognitive abilities. Accordingly, the choosing sex should be trained to solve the 
task (e.g., opening a feed box or navigating in a maze) to allow them to determine the difficulty of the given task. Only then should the choosing sex observe the learning progress of the courting sex to assess the learning ability of the prospective mates. Finally, a second mate choice test should determine a possible shift in preference. Additionally, carefully designed neurobiological experiments should help to unravel the neuronal involvement, processes, mechanisms as well as the molecular basis for cognitive mate choice, taking into account the different roles males and females play in social and sexual contexts (e.g., male/ male-, female/ female-, female/ male-, parent/offspringinteractions). Brain development, cognitive plasticity, and the plasticity of social and (sexual) incentive cooperation could have a crucial influence, as not all mate choice decisions are driven by competition exclusively.

\section{REFERENCES}

Ågmo, A. (2011). On the intricate relationship between sexual motivation and arousal. Horm. Behav. 59, 681-688. doi: 10.1016/j.yhbeh.2010.08.013

Anderson, A. P., Rose, E., Flanagan, S. P., and Jones, A. G. (2020). The estrogenresponsive transcriptome of female secondary sexual traits in the Gulf pipefish. J. Heredity 111, 294-306. doi: 10.1093/jhered/esaa008

Anderson, R. C., Searcy, W. A., Peters, S., Hughes, M., DuBois, A. L., and Nowicki, S. (2017). Song learning and cognitive ability are not consistently related in a songbird. Anim. Cogn. 20, 309-320. doi: 10.1007/s10071-016-1053-7

Andersson, M., and Simmons, L. W. (2006). Sexual selection and mate choice. Trends Ecol. Evol. 21, 296-302. doi: 10.1016/j.tree.2006.03.015

Andersson, M. B. (1994). Sexual Selection. Princeton, NJ: Princeton University Press.

Araya-Salas, M., Gonzalez-Gomez, P., Wojczulanis-Jakubas, K., López, V., and Wright, T. F. (2018). Spatial memory is as important as weapon and body size for territorial ownership in a lekking hummingbird. Sci. Rep. 8:2001.

Ariyomo, T. O., and Watt, P. J. (2013). Disassortative mating for boldness decreases reproductive success in the guppy. Behav. Ecol. 24, 1320-1326. doi: 10.1093/ beheco/art070

Astié, A. A., Kacelnik, A., and Reboreda, J. C. (1998). Sexual differences in memory in shiny cowbirds. Anim. Cogn. 1, 77-82. doi: 10.1007/s100710050011

Barlow, G. W. (2005). How do we decide that a species is sex-role reversed? Quarterly Rev. Biol. 80, 28-35.

Baur, J., Nsanzimana, J. D. A., and Berger, D. (2019). Sexual selection and the evolution of male and female cognition: a test using experimental evolution in seed beetles. Evolution 73, 2390-2400. doi: 10.1111/evo.13793

Bayne, T., Brainard, D., Byrne, R. W., Chittka, L., Clayton, N., Heyes, C., et al. (2019). What is cognition? Curr. Biol. 29, R608-R615. doi: 10.1016/j.cub.2019. 05.044

Beal, A. P., Martin, F. D., and Hale, M. C. (2018). Using RNA-seq to determine patterns of sex-bias in gene expression in the brain of the sex-role reversed Gulf Pipefish (Syngnathus scovelli). Mar. Genom. 37, 120-127. doi: 10.1016/j.margen. 2017.09.005

Beecher, M. D., and Brenowitz, E. A. (2005). Functional aspects of song learning in songbirds. Trends Ecol. Evol. 20, 143-149. doi: 10.1016/j.tree.2005.01.004

Benson-Amram, S., Dantzer, B., Stricker, G., Swanson, E. M., and Holekamp, K. E. (2016). Brain size predicts problem-solving ability in mammalian carnivores. Proc. Natl. Acad. Sci. U S A. 113, 2532-2537. doi: 10.1073/pnas.1505913113

Benson-Amram, S., and Holekamp, K. E. (2012). Innovative problem solving by wild spotted hyenas. Proc. R. Soc. B Biol. Sci. 279, 4087-4095. doi: 10.1098/rspb. 2012.1450

Berglund, A., and Rosenqvist, G. (2003). Sex role reversal in pipefish. Adv. Study Behav. 32, 131-167.

Berglund, A., Rosenqvist, G., and Svensson, I. (1986a). Mate choice, fecundity and sexual dimorphism in two pipefish species (Syngnathidae). Behav. Ecol. Sociobiol. 19, 301-307. doi: 10.1007/BF00300646

\section{AUTHOR CONTRIBUTIONS}

The author confirms being the sole contributor of this work and has approved it for publication.

\section{ACKNOWLEDGMENTS}

I thank Klaudia Witte for the opportunity to write the manuscript and her helpful comments to improve it. I thank Nils Krützfeldt for proofreading the manuscript. I also thank the University of Siegen for the financial support provided through its Open Access Publication Fund. Last but not least, I thank the guest editor for inviting me to write about this research topic, as well as both reviewers for their time and support.

Berglund, A., Rosenqvist, G., and Svensson, I. (1986b). Reversed sex roles and parental energy investment in zygotes of two pipefish (Syngnathidae) species. Mar. Ecol. Prog. Ser. 29, 209-215.

Berglund, A., Widemo, M. S., and Rosenqvist, G. (2005). Sex-role reversal revisited: choosy females and ornamented, competitive males in a pipefish. Behav. Ecol. 16, 649-655. doi: 10.1093/beheco/ari038

Boogert, N. J., Fawcett, T. W., and Lefebvre, L. (2011b). Mate choice for cognitive traits: a review of the evidence in nonhuman vertebrates. Behav. Ecol. 22, 447-459. doi: 10.1093/beheco/arq173

Boogert, N. J., Anderson, R. C., Peters, S., Searcy, W. A., and Nowicki, S. (2011a). Song repertoire size in male song sparrows correlates with detour reaching, but not with other cognitive measures. Animal Behav. 81, 1209-1216. doi: 10.1016/j.anbehav.2011.03.004

Boogert, N. J., Giraldeau, L. A., and Lefebvre, L. (2008). Song complexity correlates with learning ability in zebra finch males. Animal Behav. 76, 1735-1741. doi: 10.1016/j.anbehav.2008.08.009

Both, C., Dingemanse, N. J., Drent, P. J., and Tinbergen, J. M. (2005). Pairs of extreme avian personalities have highest reproductive success. J. Animal Ecol. 74, 667-674.

Branch, C. L., Pitera, A. M., Kozlovsky, D. Y., Bridge, E. S., and Pravosudov, V. V. (2019). Smart is the new sexy: female mountain chickadees increase reproductive investment when mated to males with better spatial cognition. Ecol. Lett. 22, 897-903.

Bray, E. E., MacLean, E. L., and Hare, B. A. (2014). Context specificity of inhibitory control in dogs. Anim. Cogn. 17, 15-31. doi: 10.1007/s10071-013-0633-z

Brodin, A., and Urhan, A. U. (2015). Sex differences in learning ability in a common songbird, the great tit - females are better observational learners than males. Behav. Ecol. Sociobiol. 69, 237-241. doi: 10.1007/s00265-014-1836-2

Byers, B. E., and Kroodsma, D. E. (2009). Female mate choice and songbird song repertoires. Animal Behav. 77, 13-22. doi: 10.1016/j.anbehav.2008.10.003

Camacho-Alpízar, A., Griffin, A. S., and Guillette, L. M. (2020). Are cognitive abilities under selection by female choice? a comment on Chen et al. (2019). Animal Behav. 165, e1-e3.

Carere, C., and Locurto, C. (2011). Interaction between animal personality and animal cognition. Curr. Zool. 57, 491-498. doi: 10.1093/czoolo/57.4.491

Cauchard, L., Boogert, N. J., Lefebvre, L., Dubois, F., and Doligez, B. (2013). Problem-solving performance is correlated with reproductive success in a wild bird population. Animal Behav. 85, 19-26.

Cauchoix, M., and Chaine, A. S. (2016). How can we study the evolution of animal minds? Front. Psychol. 7:358. doi: 10.3389/fpsyg.2016.00358

Chantal, V., Gibelli, J., and Dubois, F. (2016). Male foraging efficiency, but not male problem-solving performance, influences female mating preferences in zebra finches. PeerJ 4:e2409. doi: 10.7717/peerj.2409

Chen, B. J., Liu, K., Zhou, L. J., Gomes-Silva, G., Sommer-Trembo, C., and Plath, M. (2018). Personality differentially affects individual mate choice decisions in female and male Western mosquitofish (Gambusia affinis). PLoS One 13:e0197197. doi: 10.1371/journal.pone.0197197 
Chen, J., Zou, Y., Sun, Y. H., and ten Cate, C. (2019). Problem-solving males become more attractive to female budgerigars. Science 363, 166-167. doi: 10. 1126/science.aau8181

Clermont, J., Réale, D., and Giroux, J. F. (2019). Similarity in nest defense intensity in Canada goose pairs. Behav. Ecol. Sociobiol. 73, 1-9. doi: 10.1007/s00265-0192719-3

Cole, E. F., Morand-Ferron, J., Hinks, A. E., and Quinn, J. L. (2012). Cognitive ability influences reproductive life history variation in the wild. Curr. Biol. 22, 1808-1812. doi: 10.1016/j.cub.2012.07.051

Collins, S. M., Hatch, S. A., Elliott, K. H., and Jacobs, S. R. (2019). Boldness, mate choice and reproductive success in Rissa tridactyla. Animal Behav. 154, 67-74. doi: 10.1016/j.anbehav.2019.06.007

Corral-López, A., Bloch, N. I., Kotrschal, A., van der Bijl, W., Buechel, S. D., Mank, J. E., et al. (2017). Female brain size affects the assessment of male attractiveness during mate choice. Sci. Adv. 3:e1601990. doi: 10.1126/sciadv.1601990

Corral-López, A., Eckerström-Liedholm, S., Der Bijl, W. V., Kotrschal, A., and Kolm, N. (2015). No association between brain size and male sexual behavior in the guppy. Curr. Zool. 61, 265-273.

Corral-López, A., Kotrschal, A., and Kolm, N. (2018). Selection for relative brain size affects context-dependent male preference for, but not discrimination of, female body size in guppies. J. Exp. Biol. 221:jeb175240. doi: 10.1242/jeb. 175240

Cote, J., Dreiss, A., and Clobert, J. (2008). Social personality trait and fitness. Proc. R. Soc. B: Biol. Sci. 275, 2851-2858.

Cummings, M. E., and Ramsey, M. E. (2015). Mate choice as social cognition: predicting female behavioral and neural plasticity as a function of alternative male reproductive tactics. Curr. Opin. Behav. Sci. 6, 125-131.

da Silva, Pinto, K., Saenz, D. E., de Almeida Borghezan, E., da Silva, and Pires, T. H. (2021). Attractive males are cautious and better learners in the sailfin tetra. Animal Behav. 172, 103-111. doi: 10.1016/j.anbehav.2020.12.005

Darwin, C. (1871). The Descent of Man, and Selection in Relation to Sex. London: John Murray, doi: 10.1037/10932-000

De Kort, S. R., Emery, N. J., and Clayton, N. S. (2006). Food sharing in jackdaws, Corvus monedula: what, why and with whom? Animal Behav. 72, 297-304.

Di Lascio, F., Nyffeler, F., Bshary, R., and Bugnyar, T. (2013). Ravens (Corvus corax) are indifferent to the gains of conspecific recipients or human partners in experimental tasks. Anim. Cogn. 16, 35-43.

Dougherty, L. R., and Guillette, L. M. (2018). Linking personality and cognition: a meta-analysis. Philos. Trans. R. Soc. B: Biol. Sci. 373:20170282.

DuBois, A. L., Nowicki, S., Peters, S., Rivera-Cáceres, K. D., and Searcy, W. A. (2018). Song is not a reliable signal of general cognitive ability in a songbird. Animal Behav. 137, 205-213. doi: 10.1016/j.anbehav.2018.01.020

Dukas, R. (2004). Evolutionary biology of animal cognition. Ann. Rev. Ecol. Evol. Systemat. 35, 347-374. doi: 10.1146/annurev.ecolsys.35.112202.130152

Dukas, R. (2005). Learning affects mate choice in female fruit flies. Behav. Ecol. 16, 800-804. doi: 10.1093/beheco/ari057

Ebbesson, L. O. E., and Braithwaite, V. A. (2012). Environmental effects on fish neural plasticity and cognition. J. Fish Biol. 81, 2151-2174.

Edward, D. A. (2015). The description of mate choice. Behav. Ecol. 26, 301-310. doi: 10.1093/beheco/aru142

Edward, D. A., and Chapman, T. (2011). The evolution and significance of male mate choice. Trends Ecol. Evol. 26, 647-654. doi: 10.1016/j.tree.2011. 07.012

Endler, J. A. (1980). Natural selection on color patterns in Poecilia reticulata. Evolution 34, 76-91. doi: 10.2307/2408316

Endler, J. A. (1984). "Natural and sexual selection on color patterns in poeciliid fishes," in Evolutionary ecology of neotropical freshwater fishes, ed. T. M. Zaret (Dordrecht: Springer), 95-111.

Etheredge, R. I., Avenas, C., Armstrong, M. J., and Cummings, M. E. (2018). Sexspecific cognitive-behavioural profiles emerging from individual variation in numerosity discrimination in Gambusia affinis. Anim. Cogn. 21, 37-53. doi: 10.1007/s10071-017-1134-2

Fabre, N., García-Galea, E., and Vinyoles, D. (2014). Spatial learning based on visual landmarks in the freshwater blenny Salaria fluviatilis (Asso, 1801). Learn. Motivat. 48, 47-54. doi: 10.1016/j.lmot.2014.10.002

Farrell, T. M., Weaver, K., An, Y. S., and MacDougall-Shackleton, S. A. (2012). Song bout length is indicative of spatial learning in European starlings. Behav. Ecol. $23,101-111$.
Ferkin, M. H. (2011). Odor-related behavior and cognition in meadow voles, Microtus pennsylvanicus (Arvicolidae, Rodentia). J. Vertebrate Biol. 60, 262-276.

Ferkin, M. H. (2018). Odor communication and mate choice in rodents. Biology $7: 13$.

Fox, R. A., and Millam, J. R. (2014). Personality traits of pair members predict pair compatibility and reproductive success in a socially monogamous parrot breeding in captivity. Zoo Biol. 33, 166-172. doi: 10.1002/zoo.21121

Fuss, T., Flöck, S., and Witte, K. (2020). Sex-specific cognitive flexibility in Atlantic mollies when learning from male demonstrators exploring a new food source. Animal Behav. 173, 9-19. doi: 10.1016/j.anbehav.2020.12.012

Fuss, T., and Witte, K. (2019). Sex differences in color discrimination and serial reversal learning in mollies and guppies. Curr. Zool. 65, 323-332. doi: 10.1093/ cz/zoz029

Gabriel, P. O., and Black, J. M. (2012). Behavioural syndromes, partner compatibility and reproductive performance in Steller's jays. Ethology 118, 76-86. doi: 10.1111/j.1439-0310.2011.01990.x

Galea, L. A., Kavaliers, M., and Ossenkopp, K. P. (1996). Sexually dimorphic spatial learning in meadow voles Microtus pennsylvanicus and deer mice Peromyscus maniculatus. J. Exp. Biol. 199, 195-200.

Gatto, E., Testolin, A., Bisazza, A., Zorzi, M., and Lucon-Xiccato, T. (2020). Poor numerical performance of guppies tested in a Skinner box. Sci. Rep. 10:16724. doi: 10.1038/s41598-020-73851-1

Gaulin, S. J., and FitzGerald, R. W. (1986). Sex differences in spatial ability: an evolutionary hypothesis and test. Am. Nat. 127, 74-88. doi: 10.1086/284468

Gaulin, S. J., and FitzGerald, R. W. (1989). Sexual selection for spatial-learning ability. Animal Behav. 37, 322-331. doi: 10.1016/0003-3472(89)90121-8

Geary, D. C. (1995). Sexual selection and sex differences in spatial cognition. Learn. Individual Diff. 7, 289-301. doi: 10.1016/1041-6080(95)90003-9

Geberzahn, N., and Aubin, T. (2014). Assessing vocal performance in complex birdsong: a novel approach. BMC Biol. 12:58. doi: 10.1186/s12915-0140058-4

Girard, M. B., Elias, D. O., and Kasumovic, M. M. (2015). Female preference for multi-modal courtship: multiple signals are important for male mating success in peacock spiders. Proc. R. Soc. B: Biol. Sci. 282:20152222.

Girard, M. B., Kasumovic, M. M., and Elias, D. O. (2011). Multi-modal courtship in the peacock spider, Maratus volans (OP-Cambridge, 1874). PLoS One 6:e25390. doi: 10.1371/journal.pone.0025390

Giurfa, M., Zhang, S., Jenett, A., Menzel, R., and Srinivasan, M. V. (2001). The concepts of 'sameness' and 'difference' in an insect. Nature 410, 930-933.

Gobes, S. M., and Bolhuis, J. J. (2007). Birdsong memory: a neural dissociation between song recognition and production. Curr. Biol. 17, 789-793. doi: 10.1016/ j.cub.2007.03.059

Griebling, H. J., Rios-Cardenas, O., Abbott, J., and Morris, M. R. (2020). A study of tactical and sexual dimorphism in cognition with insights for sexual conflict. Animal Behav. 170, 43-50.

Groothuis, T. G., and Carere, C. (2005). Avian personalities: characterization and epigenesis. Neurosci. Biobehav. Rev. 29, 137-150.

Guigueno, M. F., Snow, D. A., MacDougall-Shackleton, S. A., and Sherry, D. F. (2014). Female cowbirds have more accurate spatial memory than males. Biol. Lett. 10:20140026. doi: 10.1098/rsbl.2014.0026

Guillette, L. M., Naguib, M., and Griffin, A. S. (2017). Individual differences in cognition and personality. Behav. Proc. 132, 1-3. doi: 10.1016/j.beproc.2016. 12.001

Ha, J. C., Mandell, D. J., and Gray, J. (2011). Two-item discrimination and Hamilton search learning in infant pigtailed macaque monkeys. Behav. Process. 86, 1-6. doi: 10.1016/j.beproc.2010.07.010

Hauser, M. D. (1999). Perseveration, inhibition and the prefrontal cortex: a new look. Curr. Opin. Neurobiol. 9, 214-222. doi: 10.1016/S0959-4388(99)80030-0

Hebets, E. A., and Sullivan-Beckers, L. (2019). "Mate choice and learning," in Encyclopedia of Animal Behavior, 2nd Edn, ed. J. C. Choe (London: Academic Press).

Herczeg, G., Urszán, T. J., Orf, S., Nagy, G., Kotrschal, A., and Kolm, N. (2019). Brain size predicts behavioural plasticity in guppies (Poecilia reticulata): an experiment. J. Evol. Biol. 32, 218-226.

Horton, B. M., Hauber, M. E., and Maney, D. L. (2012). Morph matters: aggression bias in a polymorphic sparrow. PLoS One 7:e48705. doi: 10.1371/journal.pone. 0048705 
Huebner, F., Fichtel, C., and Kappeler, P. M. (2018). Linking cognition with fitness in a wild primate: fitness correlates of problem-solving performance and spatial learning ability. Philos. Trans. R. Soc. B: Biol. Sci. 373:20170295.

Ihara, Y., and Feldman, M. W. (2003). Evolution of disassortative and assortative mating preferences based on imprinting. Theoretical Population Biol. 64, 193-200.

Isden, J., Panayi, C., Dingle, C., and Madden, J. (2013). Performance in cognitive and problem-solving tasks in male spotted bowerbirds does not correlate with mating success. Animal Behav. 86, 829-838. doi: 10.1016/j.anbehav.2013.07.024

Jacobs, L. F. (1996). Sexual selection and the brain. Trends Ecol. Evol. 11, 82-86. doi: 10.1016/0169-5347(96)81048-2

Jennions, M. D., and Petrie, M. (1997). Variation in mate choice and mating preferences: a review of causes and consequences. Biol. Rev. 72, 283-327. doi: $10.1017 /$ S0006323196005014

Jin, D. Z. (2013). The Neural Basis of Birdsong Syntax. Progress in Cognitive Science: From Cellular Mechanisms to Computational Theories. Beijing: Peking University Press.

Johnson-Ulrich, L., Benson-Amram, S., and Holekamp, K. E. (2019). Fitness consequences of innovation in spotted hyenas. Front. Ecol. Evol. 7:443. doi: 10.3389/fevo.2019.00443

Johnstone, R. A., Reynolds, J. D., and Deutsch, J. C. (1996). Mutual mate choice and sex differences in choosiness. Evolution 50, 1382-1391. doi: 10.1111/j.15585646.1996.tb03912.x

Jolles, J. W., Briggs, H. D., Araya-Ajoy, Y. G., and Boogert, N. J. (2019). Personality, plasticity and predictability in sticklebacks: bold fish are less plastic and more predictable than shy fish. Animal Behav. 154, 193-202.

Jones, C. M., Braithwaite, V. A., and Healy, S. D. (2003). The evolution of sex differences in spatial ability. Behav. Neurosci. 117, 403-411. doi: 10.1037/07357044.117.3.403

Jones, B. C., and DuVal, E. H. (2019). Mechanisms of social influence: a metaanalysis of the effects of social information on female mate choice decisions. Front. Ecol. Evol. 7:390. doi: 10.3389/fevo.2019.00390

Jones, C. M., and Healy, S. D. (2006). Differences in cue use and spatial memory in men and women. Proc. R. Soc. B: Biol. Sci. 273, 2241-2247.

Kaiser, M. I., and Müller, C. (2021). What is an animal personality? Biol. Philos. 36, 1-25. doi: 10.1007/s10539-020-09776-w

Kaplan, G. (2020). Long-Term attachments and complex cognition in birds and humans are linked to pre-reproductive prosociality and cooperation. constructing a hypothesis. Ann. Cogn. Sci. 4, 127-142.

Kareklas, K., Arnott, G., Elwood, R. W., and Holland, R. A. (2016). Plasticity varies with boldness in a weakly-electric fish. Front. Zool. 13:22. doi: 10.1186/s12983016-0154-0

Karino, K., Shinjo, S., and Sato, A. (2007). Algal-searching ability in laboratory experiments reflects orange spot coloration of the male guppy in the wild. Behaviour 144, 101-113. doi: 10.1163/156853907779947427

Kavaliers, M., and Choleris, E. (2017). Social cognition and the neurobiology of rodent mate choice. Int. Comp. Biol. 57, 846-856. doi: 10.1093/icb/icx042

Keagy, J., Minter, R., and Tinghitella, R. M. (2019). Sex differences in cognition and their relationship to male mate choice. Curr. Zool. 65, 285-293. doi: 10.1093/cz/ zoz014

Keagy, J., Savard, J. F., and Borgia, G. (2009). Male satin bowerbird problemsolving ability predicts mating success. Animal Behav. 78, 809-817. doi: 10 . 1016/j.anbehav.2009.07.011

Keagy, J., Savard, J. F., and Borgia, G. (2011). Complex relationship between multiple measures of cognitive ability and male mating success in satin bowerbirds, Ptilonorhynchus violaceus. Animal Behav. 81, 1063-1070. doi: 10. 1016/j.anbehav.2011.02.018

Keagy, J., Savard, J. F., and Borgia, G. (2012). Cognitive ability and the evolution of multiple behavioral display traits. Behav. Ecol. 23, 448-456. doi: 10.1093/ beheco/arr211

Kelleher, S. R., Silla, A. J., and Byrne, P. G. (2018). Animal personality and behavioral syndromes in amphibians: a review of the evidence, experimental approaches, and implications for conservation. Behav. Ecol. Sociobiol. $72,1-26$.

Kirkpatrick, M., Rand, A. S., and Ryan, M. J. (2006). Mate choice rules in animals. Animal Behav. 71, 1215-1225.

Kodric-Brown, A. (1985). Female preference and sexual selection for male coloration in the guppy (Poecilia reticulata). Behav. Ecol. Sociobiol. 17, 199-205.
Kodric-Brown, A., and Nicoletto, P. F. (2001). Female choice in the guppy (Poecilia reticulata): the interaction between male color and display. Behav. Ecol. Sociobiol. 50, 346-351. doi: 10.1007/s002650100374

Kotrschal, A., Corral-López, A., Amcoff, M., and Kolm, N. (2015). A larger brain confers a benefit in a spatial mate search learning task in male guppies. Behav. Ecol. 26, 527-532. doi: 10.1093/beheco/aru227

Kralj-Fišer, S., Sanguino Mostajo, G. A., Preik, O., Pekár, S., and Schneider, J. M. (2013). Assortative mating by aggressiveness type in orb weaving spiders. Behav. Ecol. 24, 824-831. doi: 10.1093/beheco/art030

Krebs, J. R., Sherry, D. F., Healy, S. D., Perry, V. H., and Vaccarino, A. L. (1989). Hippocampal specialization of food-storing birds. Proc. Natl. Acad. Sci. U S A. 86, 1388-1392. doi: 10.1073/pnas.86.4.1388

Labaude, S., O’Donnell, N., and Griffin, C. T. (2018). Description of a personality syndrome in a common and invasive ground beetle (Coleoptera: Carabidae). Sci. Rep. 8:17479.

Laland, K. N., and Reader, S. M. (1999). Foraging innovation in the guppy. Animal Behav. 57, 331-340. doi: 10.1006/anbe.1998.0967

Lampe, H. M., and Saetre, G. P. (1995). Female pied flycatchers prefer males with larger song repertoires. Proc. R. Soc. London. Series B: Biol. Sci. 262, 163-167. doi: 10.1098/rspb.1995.0191

Laubu, C., Schweitzer, C., Motreuil, S., Louâpre, P., and Dechaume-Moncharmont, F. X. (2017). Mate choice based on behavioural type: do convict cichlids prefer similar partners? Animal Behav. 126, 281-291.

Lindenfors, P., Gittleman, J. L., and Jones, K. E. (2007). "Sexual size dimorphism in mammals," in Sex, Size and Gender Roles: Evolutionary Studies of Sexual Size Dimorphism, eds D. J. Fairbairn, W. U. Blanckenhorn, and T. Szekely (Oxford: Oxford University Press).

Lipshutz, S. E., and Rosvall, K. A. (2020). Neuroendocrinology of sex-role reversal. Int. Comp. Biol. 60, 692-702. doi: 10.1093/icb/icaa046

Lucon-Xiccato, T., and Bisazza, A. (2014). Discrimination reversal learning reveals greater female behavioural flexibility in guppies. Biol. Lett. 10:20140206. doi: $10.1098 /$ rsbl.2014.0206

Lucon-Xiccato, T., and Bisazza, A. (2017a). Individual differences in cognition among teleost fishes. Behav. Process. 141, 184-195.

Lucon-Xiccato, T., and Bisazza, A. (2017b). Sex differences in spatial abilities and cognitive flexibility in the guppy. Animal Behav. 123, 53-60. doi: 10.1016/j. anbehav.2016.10.026

MacKinlay, R. D., and Shaw, R. C. (2019). Male New Zealand robin (Petroica longipes) song repertoire size does not correlate with cognitive performance in the wild. Intelligence 74, 25-33. doi: 10.1016/j.intell.2018.10.009

Malmkvist, J., and Hansen, S. W. (2002). Generalization of fear in farm mink, Mustela vison, genetically selected for behaviour towards humans. Animal Behav. 64, 487-501.

Martin-Wintle, M. S., Shepherdson, D., Zhang, G., Huang, Y., Luo, B., and Swaisgood, R. R. (2017). Do opposites attract? effects of personality matching in breeding pairs of captive giant pandas on reproductive success. Biol. Conserv. 207, 27-37. doi: 10.1016/j.biocon.2017.01.010

Massen, J. J., and Koski, S. E. (2014). Chimps of a feather sit together: chimpanzee friendships are based on homophily in personality. Evol. Hum. Behav. 35, 1-8. doi: 10.1016/j.evolhumbehav.2013.08.008

Massen, J. J., Ritter, C., and Bugnyar, T. (2015). Tolerance and reward equity predict cooperation in ravens (Corvus corax). Sci. Rep. 5:15021.

Mateos-Gonzalez, F., Quesada, J., and Senar, J. C. (2011). Sexy birds are superior at solving a foraging problem. Biol. Lett. 7, 668-669. doi: 10.1098/rsbl.20 11.0163

Mather, J. A., and Carere, C. (2019). "Consider the individual: personality and welfare in invertebrates," in The Welfare of Invertebrate Animals, eds C. Carere and J. Mather (Cham: Springer), 229-245.

Mather, J. A., and Logue, D. M. (2013). "The bold and the spineless: invertebrate personalities," in Animal Personalities, Behavior, Physiology, and Evolution, eds C. Carere and D. Maestripieri (Chicago, IL: University of Chicago Press).

Matthews, I. M., Evans, J. P., and Magurran, A. E. (1997). Male display rate reveals ejaculate characteristics in the Trinidadian guppy, Poecilia reticulata. Proc. R. Soc. London. Series B: Biol. Sci. 264, 695-700. doi: 10.1098/rspb.1997. 0099

Michael, N. P., Torres, R., Welch, A. J., Adams, J., Bonillas-Monge, M. E., Felis, J., et al. (2018). Carotenoid-based skin ornaments reflect foraging propensity in a seabird. Sula leucogaster. Biol. Lett. 14:20180398. 
Milinski, M., and Bakker, T. C. (1990). Female sticklebacks use male coloration in mate choice and hence avoid parasitized males. Nature 344, 330-333.

Miller, G. (2000). "Sexual selection for indicators of intelligence," in Proceedings of the Novartis Foundation Symposium, (Chichester, NY), 260-270. doi: 10.1002/ 0470870850

Miller, G. (2011). The Mating Mind: How Sexual Choice Shaped the Evolution of Human Nature. Mumbai: Anchor.

Miller, G. F., and Todd, P. M. (1998). Mate choice turns cognitive. Trends Cogn. Sci. 2, 190-198. doi: 10.1016/S1364-6613(98)01169-3

Minter, R., Keagy, J., and Tinghitella, R. M. (2017). The relationship between male sexual signals, cognitive performance, and mating success in stickleback fish. Ecol. Evol. 7, 5621-5631. doi: 10.1002/ece3.3091

Mobley, K. B., Morrongiello, J. R., Warr, M., Bray, D. J., and Wong, B. B. (2018). Female ornamentation and the fecundity trade-off in a sex-role reversed pipefish. Ecol. Evol. 8, 9516-9525. doi: 10.1002/ece3.4459

Moffat, S. D., Hampson, E., and Hatzipantelis, M. (1998). Navigation in a "virtual" maze: sex differences and correlation with psychometric measures of spatial ability in humans. Evol. Hum. Behav. 19, 73-87. doi: 10.1016/S1090-5138(97) 00104-9

Montero, A. P., Williams, D. M., Martin, J. G., and Blumstein, D. T. (2020). More social female yellow-bellied marmots, Marmota flaviventer, have enhanced summer survival. Animal Behav. 160, 113-119. doi: 10.1016/j.anbehav.2019. 12.013

Montiglio, P. O., Wey, T. W., Chang, A. T., Fogarty, S., and Sih, A. (2016). Multiple mating reveals complex patterns of assortative mating by personality and body size. J. Animal Ecol. 85, 125-135. doi: 10.1111/1365-2656.12436

Mooney, R. (2009). Neural mechanisms for learned birdsong. Learn. Mem. 16, 655-669. doi: 10.1101/lm.1065209

Munson, A. A., Jones, C., Schraft, H., and Sih, A. (2020). You're just my type: mate choice and behavioral types. Trends Ecol. Evol. 35, 823-833. doi: 10.1016/j.tree. 2020.04.010

Nicolakakis, N., Sol, D., and Lefebvre, L. (2003). Behavioural flexibility predicts species richness in birds, but not extinction risk. Animal Behav. 65, $445-452$.

Nowicki, S., Searcy, W. A., and Peters, S. (2002). Quality of song learning affects female response to male bird song. Proc. R. Soc. London Series B: Biol. Sci. 269, 1949-1954. doi: 10.1098/rspb.2002.2124

Odom, K. J., Hall, M. L., Riebel, K., Omland, K. E., and Langmore, N. E. (2014). Female song is widespread and ancestral in songbirds. Nat. Commun. 5:3379. doi: $10.1038 /$ ncomms4379

Ostojić, L., Legg, E. W., Shaw, R. C., Cheke, L. G., Mendl, M., and Clayton, N. S. (2014). Can male Eurasian jays disengage from their own current desire to feed the female what she wants? Biol. Lett. 10:20140042.

Ostojić, L., Shaw, R. C., Cheke, L. G., and Clayton, N. S. (2013). Evidence suggesting that desire-state attribution may govern food sharing in Eurasian jays. Proc. Natl. Acad. Sci. U S A. 110, 4123-4128.

Papaj, D. R., and Prokopy, R. J. (1989). Ecological and evolutionary aspects of learning in phytophagous insects. Annu. Rev. Entomol. 34, 315-350.

Patricelli, G. L., Coleman, S. W., and Borgia, G. (2006). Male satin bowerbirds, Ptilonorhynchus violaceus, adjust their display intensity in response to female startling: an experiment with robotic females. Animal Behav. 71, 49-59. doi: 10.1016/j.anbehav.2005.03.029

Patricelli, G. L., and Krakauer, A. H. (2010). Tactical allocation of effort among multiple signals in sage grouse: an experiment with a robotic female. Behav. Ecol. 21, 97-106. doi: 10.1093/beheco/arp155

Patricelli, G. L., Krakauer, A. H., and McElreath, R. (2011). Assets and tactics in a mating market: economic models of negotiation offer insights into animal courtship dynamics on the lek. Curr. Zool. 57, 225-236. doi: 10.1093/czoolo/57. 2.225

Patricelli, G. L., Uy, J. A. C., Walsh, G., and Borgia, G. (2002). Sexual selection: male displays adjusted to female's response. Nature 415, 279-280. doi: 10.1038/ $415279 \mathrm{a}$

Péron, F., John, M., Sapowicz, S., Bovet, D., and Pepperberg, I. M. (2013). A study of sharing and reciprocity in grey parrots (Psittacus erithacus). Anim. Cogn. 16, $197-210$.

Peters, S., Searcy, W. A., and Nowicki, S. (2014). Developmental stress, songlearning, and cognition. Int. Comp. Biol. 54, 555-567. doi: 10.1093/icb/ icu020
Petrazzini, M. E. M., Bisazza, A., Agrillo, C., and Lucon-Xiccato, T. (2017). Sex differences in discrimination reversal learning in the guppy. Anim. Cogn. 20, 1081-1091. doi: 10.1007/s10071-017-1124-4

Plomin, R., and Deary, I. J. (2015). Genetics and intelligence differences: five special findings. Mol. Psychiatry 20, 98-108. doi: 10.1038/mp.2014.105

Pogány, Á, Vincze, E., Szurovecz, Z., Kosztolányi, A., Barta, Z., Székely, T., et al. (2018). Personality assortative female mating preferences in a songbird. Behaviour 155, 481-503. doi: 10.1163/1568539X-00003500

Portugal, S. J., Ricketts, R. L., Chappell, J., White, C. R., Shepard, E. L., and Biro, D. (2017). Boldness traits, not dominance, predict exploratory flight range and homing behaviour in homing pigeons. Philos. Trans. R. Soc. B: Biol. Sci. 372:20160234.

Preiszner, B., Papp, S., Pipoly, I., Seress, G., Vincze, E., Liker, A., et al. (2017). Problem-solving performance and reproductive success of great tits in urban and forest habitats. Anim. Cogn. 20, 53-63.

Prokosch, M. D., Coss, R. G., Scheib, J. E., and Blozis, S. A. (2009). Intelligence and mate choice: intelligent men are always appealing. Evol. Hum. Behav. 30, 11-20. doi: 10.1016/j.evolhumbehav.2008.07.004

Rangassamy, M., Dalmas, M., Feron, C., Gouat, P., and Roedel, H. G. (2015). Similarity of personalities speeds up reproduction in pairs of a monogamous rodent. Animal Behav. 103, 7-15. doi: 10.1016/j.anbehav.2015.02.007

Range, F., Bugnyar, T., Schlögl, C., and Kotrschal, K. (2006). Individual and sex differences in learning abilities of ravens. Behav. Process. 73, 100-106. doi: 10.1016/j.beproc.2006.04.002

Reader, S. M., and Laland, K. N. (eds) (2003). Animal Innovation. Oxford: Oxford University Press.

Reader, S. M., and Laland, K. N. (2000). Diffusion of foraging innovations in the guppy. Animal Behav. 60, 175-180. doi: 10.1006/anbe.2000.1450

Réale, D., Martin, J., Coltman, D. W., Poissant, J., and Festa-Bianchet, M. (2009). Male personality, life-history strategies and reproductive success in a promiscuous mammal. J. Evol. Biol. 22, 1599-1607.

Reid, J. M., Arcese, P., Cassidy, A. L., Hiebert, S. M., Smith, J. N., Stoddard, P. K., et al. (2005). Fitness correlates of song repertoire size in free-living song sparrows (Melospiza melodia). Am. Nat. 165, 299-310.

Riebel, K. (2011). Comment on Boogert et al.: mate choice for cognitive traits or cognitive traits for mate choice? Behav. Ecol. 22, 460-461. doi: 10.1093/beheco/ arr003

Roelofs, S., Nordquist, R. E., and van der Staay, F. J. (2017). Female and male pigs' performance in a spatial holeboard and judgment bias task. Appl. Animal Behav. Sci. 191, 5-16. doi: 10.1016/j.applanim.2017.01.016

Rosenthal, G. G. (2017). Mate Choice: The Evolution of Sexual Decision Making from Microbes to Humans. Princeton, NJ: Princeton University Press.

Roth, T. C., LaDage, L. D., Freas, C. A., and Pravosudov, V. V. (2011). Variation in memory and the hippocampus across populations from different climates: a common garden approach. Proc. R. Soc. B: Biol. Sci. 279, 402-410. doi: 10.1098/ rspb.2011.1020

Ryan, M. J., Akre, K. L., and Kirkpatrick, M. (2009). "Cognitive mate choice," in Cognitive Ecology II, eds R. Dukas and J. M. Ratcliffe (Chicago, ILL: The University of Chicago Press), 137-155. doi: 10.7208/9780226169378-009

Rystrom, T. L., Bakker, T. C., and Rick, I. P. (2019). Mate assessment behavior is correlated to learning ability in female threespine sticklebacks. Curr. Zool. 65, 295-304. doi: 10.1093/cz/zoz010

Scheid, C., Schmidt, J., and Noë, R. (2008). Distinct patterns of food offering and co-feeding in rooks. Animal Behav. 76, 1701-1707. doi: 10.1016/j.anbehav. 2008.07.023

Scherer, U., Kuhnhardt, M., and Schuett, W. (2017). Different or alike? female rainbow kribs choose males of similar consistency and dissimilar level of boldness. Animal Behav. 128, 117-124. doi: 10.1016/j.anbehav.2017.04.007

Schuett, W., Godin, J. G. J., and Dall, S. R. (2011). Do female zebra finches, Taeniopygia guttata, choose their mates based on their 'personality'? Ethology 117, 908-917. doi: 10.1111/j.1439-0310.2011.01945.x

Schwab, C., Swoboda, R., Kotrschal, K., and Bugnyar, T. (2012). Recipients affect prosocial and altruistic choices in jackdaws, Corvus monedula. PLoS One 7:e34922. doi: 10.1371/journal.pone.0034922

Schweitzer, C., Melot, G., Laubu, C., Teixeira, M., Motreuil, S., and DechaumeMoncharmont, F. X. (2017). Hormonal and fitness consequences of behavioral assortative mating in the convict cichlid (Amatitlania siquia). Gen. Comp. Endocrinol. 240, 153-161. doi: 10.1016/j.ygcen.2016.10.010 
Searcy, W. A. (1984). Song repertoire size and female preferences in song sparrows. Behav. Ecol. Sociobiol. 14, 281-286. doi: 10.1007/BF00299499

Searcy, W. A., and Nowicki, S. (2019). Birdsong learning, avian cognition and the evolution of language. Animal Behav. 151, 217-227. doi: 10.1016/j.anbehav. 2019.01.015

Senar, J. C., and Escobar, D. (2002). Carotenoid derived plumage coloration in the siskin Carduelis spinus is related to foraging ability. Avian Sci. 2, 19-24.

Sewall, K. B., Soha, J. A., Peters, S., and Nowicki, S. (2013). Potential tradeoff between vocal ornamentation and spatial ability in a songbird. Biol. Lett. 9:20130344. doi: 10.1098/rsbl.2013.0344

Shaw, R. C., MacKinlay, R. D., Clayton, N. S., and Burns, K. C. (2019). Memory performance influences male reproductive success in a wild bird. Curr. Biol. 29, 1498-1502. doi: 10.1016/j.cub.2019.03.027

Sherry, D. F., and Hampson, E. (1997). Evolution and the hormonal control of sexually-dimorphic spatial abilities in humans. Trends Cogn. Sci. 1, 50-56. doi: 10.1016/S1364-6613(97)01015-2

Sherry, D. F., Jacobs, L. F., and Gaulin, S. J. (1992). Spatial memory and adaptive specialization of the hippocampus. Trends Neurosci. 15, 298-303. doi: 10.1016/ 0166-2236(92)90080-R

Shettleworth, S. J. (2001). Animal cognition and animal behaviour. Animal Behav. 61, 277-286. doi: 10.1006/anbe.2000.1606

Shettleworth, S. J. (2010). Cognition, Evolution, and Behavior, 2nd Edn. Oxford: Oxford University Press.

Shohet, A. J., and Watt, P. J. (2009). Female guppies Poecilia reticulata prefer males that can learn fast. J. Fish Biol. 75, 1323-1330. doi: 10.1111/j.1095-8649.2009. 02366.x

Sih, A., and Bell, A. M. (2008). Insights for behavioral ecology from behavioral syndromes. Adv. Study Behav. 38, 227-281. doi: 10.1016/S0065-3454(08) 00005-3

Sih, A., and Del Giudice, M. (2012). Linking behavioural syndromes and cognition: a behavioural ecology perspective. Philos. Trans. R. Soc. B: Biol. Sci. 367, 2762-2772. doi: 10.1098/rstb.2012.0216

Sih, A., Spiegel, O., Godfrey, S., Leu, S., and Bull, C. M. (2018). Integrating social networks, animal personalities, movement ecology and parasites: a framework with examples from a lizard. Animal Behav. 136, 195-205. doi: 10.1016/j. anbehav.2017.09.008

Silk, J. B., and Kappeler, P. M. (2017). "Sociality in primates," in Comparative Social Evolution, eds D. R. Rubenstein and P. Abbot (Cambridge: Cambridge University Press), 253-283. doi: 10.1017/9781107338319.010

Smith, C., Philips, A., and Reichard, M. (2015). Cognitive ability is heritable and predicts the success of an alternative mating tactic. Proc. R. Soc. B: Biol. Sci. 282:20151046. doi: 10.1098/rspb.2015.1046

Snell-Rood, E. C. (2013). An overview of the evolutionary causes and consequences of behavioural plasticity. Animal Behav. 85, 1004-1011. doi: 10.1016/j.anbehav. 2012.12.031

Snowberg, L. K., and Benkman, C. W. (2009). Mate choice based on a key ecological performance trait. J. Evol. Biol. 22, 762-769. doi: 10.1111/j.1420-9101.2009. 01699.x

Sol, D., Duncan, R. P., Blackburn, T. M., Cassey, P., and Lefebvre, L. (2005). Big brains, enhanced cognition, and response of birds to novel environments. Proc. Natl. Acad. Sci. U S A. 102, 5460-5465. doi: 10.1073/pnas.0408145102

Sonnenberg, B. R., Branch, C. L., Pitera, A. M., Bridge, E., and Pravosudov, V. V. (2019). Natural selection and spatial cognition in wild food-caching mountain chickadees. Curr. Biol. 29, 670-676. doi: 10.1016/j.cub.2019.01.006

Spritzer, M. D., Meikle, D. B., and Solomon, N. G. (2005). Female choice based on male spatial ability and aggressiveness among meadow voles. Animal Behav. 69, 1121-1130. doi: 10.1016/j.anbehav.2004.06.033

Stamps, J., and Groothuis, T. G. (2010). The development of animal personality: relevance, concepts and perspectives. Biol. Rev. 85, 301-325. doi: 10.1111/j. 1469-185X.2009.00103.x

Stanley, C. R., Mettke-Hofmann, C., and Preziosi, R. F. (2017). Personality in the cockroach Diploptera punctata: evidence for stability across developmental stages despite age effects on boldness. PLoS One 12:e0176564. doi: 10.1371/ journal.pone. 0176564

Striedter, G. F., and Burley, N. T. (2019). Are clever males preferred as mates? Science 363, 120-121. doi: 10.1126/science.aaw1811
Sznajder, B., Sabelis, M. W., and Egas, M. (2012). How adaptive learning affects evolution: reviewing theory on the Baldwin effect. Evol. Biol. 39, 301-310. doi: 10.1007/s11692-011-9155-2

Templeton, C. N., Laland, K. N., and Boogert, N. J. (2014). Does song complexity correlate with problem-solving performance in flocks of zebra finches? Animal Behav. 92, 63-71. doi: 10.1016/j.anbehav.2014.03.019

Toms, C. N., Echevarria, D. J., and Jouandot, D. J. (2010). A methodological review of personality-related studies in fish: focus on the shy-bold axis of behavior. Int. J. Comp. Psychol. 23, 1-25.

van Oers, K., Drent, P. J., Dingemanse, N. J., and Kempenaers, B. (2008). Personality is associated with extrapair paternity in great tits. Parus major. Animal Behav. 76, 555-563. doi: 10.1016/j.anbehav.2008.03.011

Van Oosterhout, C., Trigg, R. E., Carvalho, G. R., Magurran, A. E., Hauser, L., and Shaw, P. W. (2003). Inbreeding depression and genetic load of sexually selected traits: how the guppy lost its spots. J. Evol. Biol. 16, 273-281. doi: 10.1046/j.1420-9101.2003.00511.x

Vincent, A., Ahnesjö, I., Berglund, A., and Rosenqvist, G. (1992). Pipefishes and seahorses: are they all sex role reversed? Trends Ecol. Evol. 7, 237-241. doi: 10.1016/0169-5347(92)90052-D

von Bayern, A. M., de Kort, S. R., Clayton, N. S., and Emery, N. J. (2007). The role of food-and object-sharing in the development of social bonds in juvenile jackdaws (Corvus monedula). Behaviour 144, 711-733. doi: 10.1163/ 156853907781347826

Wallace, K. J., and Hofmann, H. A. (2021). Equal performance but distinct behaviors: sex differences in a novel object recognition task and spatial maze in a highly social cichlid fish. Anim. Cogn. 24, 1057-1073.

Wallace, K. J., Rausch, R. T., Ramsey, M. E., and Cummings, M. E. (2020). Sex differences in cognitive performance and style across domains in mosquitofish (Gambusia affinis). Anim. Cogn. 23, 655-669. doi: 10.1007/s10071-020-01367-2

Walton, A., and Toth, A. L. (2016). Variation in individual worker honey bee behavior shows hallmarks of personality. Behav. Ecol. Sociobiol. 70, 999-1010. doi: 10.1007/s00265-016-2084-4

Wetzel, D. P. (2017). Problem-solving skills are linked to parental care and offspring survival in wild house sparrows. Ethology 123, 475-483. doi: 10.1111/ eth. 12618

Wey, T. W., and Blumstein, D. T. (2012). Social attributes and associated performance measures in marmots: bigger male bullies and weakly affiliating females have higher annual reproductive success. Behav. Ecol. Sociobiol. 66, 1075-1085. doi: 10.1007/s00265-012-1358-8

Williams, D. M., Wu, C., and Blumstein, D. T. (2020). Social position indirectly influences the traits yellow-bellied marmots use to solve problems. Anim. Cogn. 24, 829-842. doi: 10.1007/s10071-020-01464-2

Witte, K., Kniel, N., and Kureck, I. M. (2015). Mate-choice copying: status quo and where to go. Curr. Zool. 61, 1073-1081. doi: 10.1093/czoolo/61.6.1073

Zoratto, F., Cordeschi, G., Grignani, G., Bonanni, R., Alleva, E., Nascetti, G., et al. (2018). Variability in the "stereotyped" prey capture sequence of male cuttlefish (Sepia officinalis) could relate to personality differences. Animal Cogn. 21, 773-785. doi: 10.1007/s10071-018-1209-8

Conflict of Interest: The author declares that the research was conducted in the absence of any commercial or financial relationships that could be construed as a potential conflict of interest.

Publisher's Note: All claims expressed in this article are solely those of the authors and do not necessarily represent those of their affiliated organizations, or those of the publisher, the editors and the reviewers. Any product that may be evaluated in this article, or claim that may be made by its manufacturer, is not guaranteed or endorsed by the publisher.

Copyright (c) 2021 Fuss. This is an open-access article distributed under the terms of the Creative Commons Attribution License (CC BY). The use, distribution or reproduction in other forums is permitted, provided the original author $(s)$ and the copyright owner(s) are credited and that the original publication in this journal is cited, in accordance with accepted academic practice. No use, distribution or reproduction is permitted which does not comply with these terms. 